\title{
VIOLÊNCIA E PODER EM HANNAH ARENDT
}

\author{
Violence and Power in Hannah Arendt
}

Karla Pinhel Ribeiro ${ }^{1}$

\begin{abstract}
RESUMO
O artigo busca apresentar a concepção arendtiana de direito e violência a partir do estudo de sua obra Sobre a violência (1969). O objetivo é demonstrar a distinção que a autora adota entre os conceitos de poder e violência, principalmente na relação com a política e o direito. A metodologia utilizada foi a análise do texto de Hannah Arendt e de alguns de seus comentadores. A conclusão do artigo defende, de acordo com Arendt, que poder e violência são fenômenos distintos, onde o fenômeno da violência ocorre quando há ausência de poder.

Palavras-chave: Política; violência; poder; direito; Hannah Arendt.
\end{abstract}

\begin{abstract}
The paper aims at present arendtian conception of violence by the study of her work On violence (1969). The objective is to demonstrate the autor distinction of the concepts of power and violence, specially on the relation with politics and law. The methodology utilized was the bibliography analisys of the work of Hannah Arendt with some of her commentators. The conclusion of the paper argues with Hannah Arendt that power and violence are different phenomena, where the occurrence of violence happens when there is lack of power.
\end{abstract}

Key-words: Politics; violence; power; law; Hannah Arendt.

INTRODUÇÃO

"Um dia passado nas favelas de qualquer grande cidade teria sido suficiente." Hannah Arendt, Sobre a violência

Hannah Arendt considera o fenômeno da violência como denominador comum do século vinte. Para ela, a violência, diferentemente do poder, da força e da coerção necessita de implementos. Para ela a violência sempre ocupou uma posição importante nos assuntos humanos, mas raramente foi objeto de consideração especial. Um exemplo disso citado pela filósofa está na edição de 1969 da Enciclopédia de Ciências Sociais americana que não possui menção para o termo "violência". Esta é uma indicação, segundo Hannah Arendt, de que a violência é considerada um fenômeno cotidiano e, por isso, negligenciada. Ela diz: "Ninguém interroga ou examina o que é óbvio para todo mundo"2.

De acordo com Hannah Arendt, a violência nos registros do passado foi considerada um fenômeno marginal. Para ela, todas as antigas verdades sobre a relação entre guerra e política, ou a

\footnotetext{
${ }^{1}$ Doutora em Filosofia pela Universidade de São Paulo (USP), Mestre em Filosofia pela Universidade Federal de Santa Catarina (UFSC). Pesquisadora visitante na Akademie der Künste, Walter Benjamin Archiv, Alemanha. Professora de Filosofia e Ciência Política do Centro Universitário Curitiba (UNICURITIBA).

2 ARENDT, Hannah. Sobre a violência. Rio de Janeiro: Editora Civilização Brasileira, 2011, p. 23.
} 


\section{VIOLÊNCIA E PODER EM HANNAH ARENDT}

respeito de violência e poder se tornaram inaplicáveis: "A Segunda Guerra Mundial não foi seguida pela paz, mas por uma Guerra Fria, e o estabelecimento de um complexo de trabalho industrial-militar;" "a paz é a continuação da guerra por outros meios." Compara a violência dos estudantes negros com a violência dos trabalhadores dos Estados Unidos: "Força e violência provavelmente serão técnicas de controle social e persuasão bem sucedidas quando tiverem o apoio popular”’.

Em Sobre a violência, Hannah Arendt analisa a questão da violência no domínio da política. Segundo ela, para a grande maioria dos autores a violência é considerada a mais flagrante forma de poder. Além disso, ela mesma se questiona sobre a possibilidade da violência desaparecer entre os Estados e se isto significaria o fim do poder. Seu propósito, todavia, consiste em diferenciar poder e violência. Para ela, poder e violência não são o mesmo. A diferença consiste em que o poder precisa de números e a violência não; a violência precisa de implementos, propiciados pela tecnologia. A forma extrema de poder é Todos contra Um; a forma extrema de violência é Um contra Todos"'. As diferenças entre violência, poder, autoridade e força não são apenas lógicas e gramaticais, mas históricas. As diferenças da violência precisam ser explicitados em dois domínios diferentes, o do povo e o do Estado. Para ela: "Nunca existiu governo exclusivamente baseado nos meios da violência"'s. O poder é de fato a essência de todo governo, mas a violência não.

\section{PODER E VIOLÊNCIA: UMA DISTINÇÃO}

Dentro desse contexto, cabe destacar as distinções conceituais que ela faz:

1) Poder: não se atribui à pessoa individualmente, mais a um grupo;

2) Vigor: designa alguma coisa singular, uma entidade individual, usado sem metáfora, trata-se da força como qualidade do forte;

3) Força: força e vigor são usadas no discurso cotidiano como sinônimo de violência, como nos exemplos "forças da natureza" e "forças das circunstâncias";

4) Autoridade: o mais impreciso destes fenômenos e, no entanto, o mais abusado, que pode ser investido em pessoas, algo como uma autoridade pessoal, tal qual pode ser observada nas relações entre pais e filhos, professor e aluno, senador romano e padre da igreja. Requer respeito para não haver perda da autoridade;

5) Violência: distinta por seu caráter instrumental. Fenomenologicamente, aproxima-se da coerção que serve para implementar a violência, mas tal como outros instrumentos, não pode substituí-

\footnotetext{
3 ARENDT, Hannah. Sobre a violência. Rio de Janeiro: Editora Civilização Brasileira, 2011, p. 35.

${ }^{4}$ ARENDT, Hannah. Sobre a violência. Rio de Janeiro: Editora Civilização Brasileira, 2011, p. 58.

${ }^{5}$ ARENDT, Hannah. Sobre a violência. Rio de Janeiro: Editora Civilização Brasileira, 2011, p. 67.

${ }^{6}$ ARENDT, Hannah. On Violence. New York: Harcourt, 1969, p. 44-46.
} 
la.

Poder e violência, embora sejam fenômenos diferentes, geralmente aparecem juntos. Hannah Arendt compreende o governo como a dominação do homem sobre o homem através dos meios da violência. Para ela, a violência pode sempre destruir o poder. A dominação da pura violência vem de onde o poder está sendo perdido. Para resumir, politicamente falando, é insuficiente dizer que poder e violência não são o mesmo. Para Hannah Arendt, poder e violência podem ser os opostos; quando um domina absolutamente, o outro está ausente.

Hannah Arendt fala também das causas e natureza da violência. Não há necessidade do grande esforço dos cientistas naturais em tentar solucionar o problema da violência no comportamento humano estudando ratos, formigas, peixes e macacos, com o propósito de dizer que a superpopulação resulta em agressividade. "Um dia passado nas favelas de qualquer grande cidade teria sido suficiente" 7 . Os resultados das pesquisas tanto das ciências sociais quanto das ciências naturais tendem a fazer do comportamento violento uma reação mais natural do que se estaria preparado em admitir em sua ausência. A violência sem provocação é natural? Argumenta que a violência não é "nem bestial nem irracional", não importando se se entendem esses termos na linguagem corrente dos humanistas ou de acordo com as teorias científicas naturais.

Assim, Hannah Arendt explica que dizer que a violência advém da raiva é um lugar-comum e que a raiva pode ser irracional ou patológica, mas isso vale para qualquer outro sentimento humano. A raiva não consiste em uma reação automática da miséria ou sofrimento, a uma doença incurável ou a um terremoto, ou a condições sociais que parecem imutáveis. A raiva aparece somente quando há motivos para supor que as condições poderiam ser mudadas, mas não são.

Não há dúvida de que é possível criar condições sob as quais os homens são desumanizados tais como os campos de concentração, a tortura, a fome -, mas isso não significa que eles se tornem semelhantes a animais; e sob tais condições, o mais claro indício da desumanização não são a raiva e a violência, mas a sua ausência conspícua ${ }^{8}$.

Para Hannah Arendt, agimos com raiva quando nosso senso de justiça é ofendido em certas circunstâncias; a violência, isto é, o agir sem argumentar, sem o discurso ou sem contar com as consequências, é o único modo de reequilibrar as balanças da justiça. O recurso à violência diante de acontecimentos e condições ultrajantes é sempre uma experiência tentadora em razão de sua inerência imediatista e sua prontidão. A urgência de uma ação deliberada é contrária à natureza da violência, porém não é isso que a torna irracional. Ao contrário, tanto a vida privada como a vida pública possuem exemplos de que a prontidão de um ato violento serve de remédio imediato. Assim, raiva e violência para Hannah Arendt pertencem às emoções da natureza humana e eliminá-las seria também uma forma de

${ }^{7}$ ARENDT, Hannah. Sobre a violência. Rio de Janeiro: Editora Civilização Brasileira, 2011, p. 77.

8 ARENDT, Hannah. Sobre a violência. Rio de Janeiro: Editora Civilização Brasileira, 2011, p. 81. 
desumanizar e castrar o homem. Em certas circunstâncias nas quais "os homens tomam a lei em suas próprias mãos para o bem da justiça" "9 podem estar em desacordo com as constituições das civilizações, porém apesar de sua característica antipolítica não significa que sejam inumanos ou simplesmente emocionais. Raiva e violência para Hannah Arendt se tornam irracionais apenas quando dirigidas contra seus "substitutos".

Segundo Hannah Arendt, poucos autores de alta envergadura exaltaram a violência pela violência, entre estes Sorel, Pareto e Fanon, foram motivados pelo ódio à sociedade burguesa e conduzidos a uma grande ruptura de padrões morais.

Tirar a máscara da hipocrisia da face do inimigo, desmascará-lo e desmascarar as maquinações e manipulações diabólicas que lhe permitem dominar sem se valer de meios violentos, quer dizer, provocar a ação mesmo sob o risco da aniquilação, de sorte que a verdade possa aparecer - esses ainda estão entre os mais fortes motivos da violência de hoje nos campi e nas ruas ${ }^{10}$.

É preciso salientar que essa violência não é irracional. Considerando que os homens vivem num mundo de aparências e dependem, para se manifestar, da dissimulação da hipocrisia, diferentemente da desenvoltura e ardil que aparecem com a revelação no devido tempo, para Hannah Arendt, apenas é possível confiar nas palavras quando temos certeza de que sua função é revelar e não esconder. A reação violenta contra a hipocrisia, embora possa ser justificável em termos, perde sua razão de ser quando busca um objetivo estratégico próprio, isto é, torna-se "irracional" quando é "racionalizada".

Muito embora a violência não necessite de números para ser eficiente, como no exemplo citado pela filósofa: "um homem com uma metralhadora pode dar conta de centenas de pessoas bem organizadas"11, é em sua modalidade coletiva que surge sua característica mais perigosa, que não está relacionada com números. Hannah Arendt concorda que tanto nas ações militares quanto nas revolucionárias o individualismo é o primeiro valor a desaparecer. No lugar dele, encontra-se uma coesão de grupo sentida e que prova ser um vínculo forte. É certo que em empreendimentos ilegais os grupos criminosos ou políticos, por segurança, exigirão que cada um cometa uma ação irrevogável com a finalidade de romper a ponte com a sociedade respeitável e assim ser admitido na comunidade da violência.

Mas, uma vez que um homem é admitido, ele sucumbirá ao encantamento inebriante da prática da violência [que] amarra os homens em um todo coeso, pois cada indivíduo forma um elo violento na grande cadeia, torna-se uma parte do grande organismo da violência em expansão ${ }^{12}$.

Nas análises de Hannah Arendt, ela observa que:

\footnotetext{
${ }^{9}$ ARENDT, Hannah. Sobre a violência. Rio de Janeiro: Editora Civilização Brasileira, 2011, p. 82.

10 ARENDT, Hannah. Sobre a violência. Rio de Janeiro: Editora Civilização Brasileira, 2011, p. 84-85.

11 ARENDT, Hannah. Sobre a violência. Rio de Janeiro: Editora Civilização Brasileira, 2011, p. 85.

12 ARENDT, Hannah. Sobre a violência. Rio de Janeiro: Editora Civilização Brasileira, 2011, p. 86.
} 
É como se a própria vida, a vida imortal da espécie, alimentada, por assim dizer, pela morte contínua de seus membros individuais, estivesse em 'expansão', fosse realizada na prática da violência ${ }^{13}$

Seja como for, Hannah Arendt diz desconhecer algum corpo político fundado diante da igualdade da morte e na prática da violência. Porém, ela afirma que fortes sentimentos de fraternidade originados pela violência coletiva já desencaminharam muitas pessoas boas pela esperança de, a partir dela, fazerem surgir uma nova comunidade política e um homem novo.

No pensamento de Hannah Arendt, a compreensão de poder e violência em termos biológicos pela tradição organicista ocidental é o que há de mais teoricamente perigoso. Da mesma forma que estes termos são interpretados atualmente com fundamento na vida e sua criatividade, a violência é justificada com fundamento na criatividade. As metáforas orgânicas que atravessam as discussões contemporâneas sobre poder e violência, de forma especial sobre os tumultos, como a noção de uma "sociedade enferma" na qual os tumultos são os sintomas, todavia, só podem promover ainda mais a violência. Assim, segundo Arendt, a discussão entre aqueles que propõem meios violentos para a restauração da "lei e ordem" e aqueles que propõem reformas não violentas soam como um debate entre médicos que discutem as condições de uma intervenção cirúrgica ou um tratamento clínico de um paciente. Nesse sentido, quanto mais doente estiver o paciente, maior é a chance de o cirurgião estar com a razão.

Hannah Arendt também lembra que, a partir do momento em que se começa a falar de violência e poder em termos não políticos, mas biológicos, os exaltadores da violência podem fazer apelação ao fato de que na natureza, criar e destruir são partes do processo natural, onde a ação de violência coletiva possa parecer tão natural como a condição de vida em sociedade da humanidade, quanto a luta para sobreviver e "a morte violenta para continuação da vida animal"14.

A violência, tendo natureza instrumental é racional na medida em que se torna eficiente em atingir o fim que deve ser justificado. E, considerando-se que quando em ação não se sabe ao certo quais consequências ao final serão alcançadas, a violência só terá aparência de racionalidade se objetivada em curto prazo. A violência não propõe causas, não propõe a história e tão pouco a revolução, muito menos o progresso ou o retrocesso, porém, pode servir para a dramatização de reclamações e levá-las a público. O perigo da violência, mesmo quando é movida dentro de uma consciente margem de estrutura e objetivos de curto prazo de caráter não extremo será sempre aquele que os meios se sobrepõem aos fins.

Se os objetivos não são alcançados rapidamente, o resultado será não apenas a derrota, mas a introdução da prática da violência na totalidade do corpo político. A ação é irreversível, e um retorno ao status quo em caso de derrota é sempre improvável. A prática da violência, como toda ação, muda o mundo, mas a mudança mais provável é para um mundo mais violento ${ }^{15}$.

\footnotetext{
13 ARENDT, Hannah. Sobre a violência. Rio de Janeiro: Editora Civilização Brasileira, 2011, p. 87.

14 ARENDT, Hannah. Sobre a violência. Rio de Janeiro: Editora Civilização Brasileira, 2011, p. 95.

15 ARENDT, Hannah. Sobre a violência. Rio de Janeiro: Editora Civilização Brasileira, 2011, p. 100-101.
} 
Para Hannah Arendt, nem o poder nem a violência são fenômenos naturais, ou seja, "uma manifestação do processo vital"16. O poder e a violência pertencem ao espaço político que envolve os negócios humanos, caracterizados pela propensão a iniciar algo novo.

\section{EM BUSCA DE UM LUGAR NO MUNDO: REPENSAR O FENÔMENO DA VIOLÊNCIA}

Silvia Gombi Borges dos Santos em sua obra Em busca de um lugar no mundo: o conceito de violência em Hannah Arendt, em um capítulo dedicado à distinção arendtiana entre violência e poder ressalta o reconhecimento de que, embora a violência tenha exercido um papel muito importante na história e na política humana, os estudiosos tenham lhe dedicado pouca atenção, enquanto objeto de investigação teórica. No capítulo referido, Santos sustenta a hipótese de distinção entre violência e poder no pensamento de Hannah Arendt:

Ainda que frequentemente apareçam juntos, confundindo-se, há uma distinção conceitual entre
ambos, na medida em que se opõem. Para ela [Hannah Arendt], ocorre uma precedência do poder
sobre a violência em sua especificidade, e separá-la de seus implementos, com os quais muitas
vezes se confunde; e por sua banalização e arbitrariedade no plano dos fatos, teria permanecido
como fenômeno marginal na tradição do pensamento filosófico ${ }^{17}$.

De acordo com Santos (2011), Hannah Arendt recusa a ideia de que existe no ser humano um instinto inato de dominação e agressividade, bem como a ideia de que existem de modo natural pessoas mais dispostas à obediência e outras com disposição maior a mandar. Segundo a comentadora, Arendt busca fundamento para sua posição no pensamento da Antiguidade clássica greco-romana, principalmente no que se refere às concepções de lei e direito. Para ela, a tese sustentada por Hannah Arendt é a de que:

Com base em dois conceitos fundamentais - de isonomia, ou "igualdade perante a lei", retirado da cidade-Estado grega, e civitas, ou "condição de cidadão, direito de cidadão", buscado no mundo romano - é possível chegar a um conceito de poder e lei, cuja essência não se baseie na relação mando-obediência, e que não identifique poder e domínio ou lei e mando ${ }^{18}$.

Segundo Santos (2011), a originalidade do conceito de poder de Hannah Arendt consiste em situar a fonte de todo o poder no povo, e não em leis ou implementos de violência. Para Hannah Arendt, é o "povo que confere poder às instituições de um país, e este apoio não é mais do que a continuação do consentimento que trouxe as leis à existência"19. Em Condição Humana, Hannah Arendt afirma também

\footnotetext{
${ }^{16}$ ARENDT, Hannah. Sobre a violência. Rio de Janeiro: Editora Civilização Brasileira, 2011, p. 103.

${ }^{17}$ SANTOS, Silvia Gombi. Em busca de um lugar no mundo: o conceito de violência em Hannah Arendt. São Paulo: Editora Perspectiva, 2011, p. 01.

${ }^{18}$ ARENDT, Hannah. Sobre a violência. Rio de Janeiro: Editora Civilização Brasileira, 2011, p. 02.

${ }^{19}$ ARENDT, Hannah. Sobre a violência. Rio de Janeiro: Editora Civilização Brasileira, 2011, p. 02; SANTOS, Silvia Gombi. Em busca de um lugar no mundo: o conceito de violência em Hannah Arendt. São Paulo: Editora Perspectiva, 2011, p. 34.
} 
que: "é o poder que mantém a existência da esfera pública, o espaço potencial da aparência entre homens que agem e falam"20.

A especificidade da violência em Hannah Arendt, segundo Santos (2011), consiste em sua natureza instrumental:

O poder é de fato a essência de todo governo, mas não a violência. A violência é por natureza instrumental; como todos os meios, ela sempre depende da orientação e da justificação pelo fim que almeja. E aquilo que necessita de justificação por outra coisa não pode ser a essência de nada ${ }^{21}$.

Em sua obra O conceito de violência em Hannah Arendt, Santos (2011), no capítulo denominado Violência e poder, procura traçar de maneira específica, as aproximações e os limites destes conceitos no pensamento de Hannah Arendt. Nesse sentido, Silvia Gombi diz que, para Hannah Arendt, o poder exclui o emprego da violência e não precisa de justificação, sendo sua existência inerente às comunidades políticas; ele surge quando da união e da ação das pessoas em concerto. Entretanto, já a violência precisa ser justificada; e de acordo com Hannah Arendt, a violência só pode ser justificada quando há perigo iminente para o indivíduo, no caso de legítima defesa, ou no caso do Estado, quando um criminoso desafia a lei. Afora essas duas hipóteses, a violência não tem justificativa.

Deste modo, segundo a comentadora, poder e não violência são termos correlatos, onde a não violência estaria ligada a uma forma mais passiva de manifestação de poder ${ }^{22}$, destacando que, para Hannah Arendt, a violência é um fenômeno cultural que surge ao se tentar acabar com a hipocrisia, com a mentira e com a injustiça. Assim, Hannah Arendt, ao investigar a natureza e a causa da violência conclui de forma negativa pela irracionalidade e bestialidade da violência.

Todavia, além das duas hipóteses previstas em Sobre a violência por Hannah Arendt para se justificar a violência, Santos (2011) encontra em Da revolução outra hipótese de justificativa da violência como elemento que caracteriza tanto guerras como revoluções, a saber: o uso da violência para se obter a liberdade; e que se apresenta quando se instauram novas realidades. Assim, a característica de novidade parece ser o elemento determinante para se identificar uma revolução e em se justificar o uso da violência.

Considerando, desse modo, que uma revolução não seja uma simples mudança, mas se constitua em um evento cuja principal característica é a novidade, a violência frequentemente nada mais é que o meio, o recurso para viabilizar esse 'novo', e é precisamente nesse sentido que ela é justificada ${ }^{23}$.

\footnotetext{
20 ARENDT, Hannah. Human Condition. Chicago: The University of Chicago Press, 1998, p. 212.

${ }^{21}$ ARENDT, Hannah. Sobre a violência. Rio de Janeiro: Editora Civilização Brasileira, 2011, p. 40-41; SANTOS, Silvia Gombi. Em busca de um lugar no mundo: o conceito de violência em Hannah Arendt. São Paulo: Editora Perspectiva, 2011, p. 07.

22 SANTOS, Silvia Gombi. Em busca de um lugar no mundo: o conceito de violência em Hannah Arendt. São Paulo: Editora Perspectiva, 2011, p. 14.

${ }^{23}$ SANTOS, Silvia Gombi. Em busca de um lugar no mundo: o conceito de violência em Hannah Arendt. São Paulo: Editora Perspectiva, 2011, p. 14.
} 
Por sua vez, André Duarte, em seu ensaio crítico Poder e violência no pensamento político de Hannah Arendt: uma reconsideração, inicialmente observa que a obra de Hannah Arendt, Sobre a violência:

\begin{abstract}
Não tinha pretensão de ser um tratado sistemático a respeito da violência e do poder, tampouco tinha a pretensão de propor soluções teóricas para aqueles dilemas. Tratava-se, antes, de uma reflexão filosófica sobre determinados acontecimentos particulares, tomados como ocasião para contestar a tese de que poder e violência sejam fenômenos equiparáveis e, portanto, intercambiáveis, bem como a tese de que o fundamento do poder seja a violência, concepções presentes entre aqueles agentes políticos dos anos 1960 que Arendt denominou os glorificadores da violência. $\mathrm{O}$ aspecto fundamental que pretendo ressaltar em meu comentário é que Arendt não se limitou a estabelecer a importante e polêmica distinção entre poder e violência, pois também pensou, a partir dessa distinção, que poder e violência sempre se relacionam entre si nas situações políticas concretas, aspecto para o qual não se tem atestado suficientemente na literatura secundária 24
\end{abstract}

Duarte (2000) destaca, em nota, que o centro gravitacional de discussão teórica de Hannah Arendt em Sobre a violência é a relação poder-violência, razão pela qual a filósofa intitulou a versão em alemão de Macht und Gewalt (2014), isto é, poder e violência. Segundo ele, é preciso pensar as distinções conceituais feitas por Hannah Arendt ao longo do texto de maneira relacional, tendo em mente que aquilo o que se distingue mantém uma relação de pertencimento com aquilo de que se distingue. Hannah Arendt reconhece que na vida política não há limite absoluto, este sempre é tênue e capaz de contaminar e se deslocar (ARENDT, 1963). Para exemplificar esse caráter relacional das distinções de Hannah Arendt, André Duarte propõe pensarmos em uma fronteira, que não tem apenas a função de separar dois lugares, mas também unificá-los: "todo limite estabelece uma partilha ao mesmo tempo em que vincula opostos que aí se separam, os quais compartilham o limite e se unificam justamente ali onde se separam"25.

De acordo com André Duarte, poder, dominação, obediência, coerção e violência são noções que, apesar de diferentes, são desencadeadas logicamente de modo fácil entre si, e sua consequência principal é o obscurecimento do fenômeno não violento em essência da criação do poder por meio da ação coletiva e em conjunto, realizada pelo discurso e pelo debate. Para Hannah Arendt,

por trás da aparente confusão subjaz a firme convicção à luz da qual todas as distinções seriam, no melhor dos casos, de pouca importância: a convicção de que o tema político crucial é, e sempre foi, a questão sobre 'quem domina quem'26.

Em Hannah Arendt, o poder se fundamenta no apoio, seja ele tácito ou explícito, e no número

\footnotetext{
${ }^{24}$ ARENDT, Hannah. Sobre a violência. Rio de Janeiro: Editora Civilização Brasileira, 2011, p. 132-133; DUARTE, André. O pensamento à sombra da ruptura: política e filosofia em Hannah Arendt. São Paulo: Paz e Terra, 2000.

25 ARENDT, Hannah. Sobre a violência. Rio de Janeiro: Editora Civilização Brasileira, 2011, p. 135; DUARTE, André. O pensamento à sombra da ruptura: política e filosofia em Hannah Arendt. São Paulo: Paz e Terra, 2000.

${ }^{26}$ ARENDT, Hannah. The origins of totalitarianism. New York: Harcourt, 1966, p. 517; Sobre a violência. Rio de Janeiro: Editora Civilização Brasileira, 2011, p. 145; DUARTE, André. O pensamento à sombra da ruptura: política e filosofia em Hannah Arendt. São Paulo: Paz e Terra, 2000.
} 
de pessoas que nele consentem, e não nos meios de violência de que se possui. E é com este pressuposto em mente que é possível fazer uma compreensão do conceito de direito em Hannah Arendt. Segundo André Duarte, em Hannah Arendt a função das leis é: "erigir fronteiras e estabelecer canais de comunicação entre os homens"27, com a finalidade de proporcionar estabilidade para um mundo que tem a marca da mudança como essência, mutação esta que os seres humanos novos trazem consigo em potência. Para Duarte (2000), este papel estabilizador do direito e das leis em Hannah Arendt não tem nada a ver com o conservadorismo que considera as leis e o direito imutáveis, pois, para Hannah Arendt, a mudança faz parte da constituição da condição humana. Ele afirma que:

Seu argumento [de Hannah Arendt] é que toda civilização está assentada sobre uma estrutura de estabilidade que proporciona o cenário para o fluxo de mudança. As leis e o direito circunscrevem cada novo começo trazido ao mundo por meio da ação, devendo assegurar um espaço de liberdade e movimento ao mesmo tempo em que impõe limites à criatividade humana. Assim, os limites das leis positivas constituem a garantia de um mundo comum capaz de durar para além da fugaz duração individual de cada geração, absorvendo e alimentado a possibilidade de novidade ${ }^{28}$.

\section{CONSIDERAÇÕES FINAIS}

O presente artigo buscou apresentar a distinção arendtiana entre poder e violência, mostrando que, para esta autora, o poder não se confunde com a violência.

Para Arendt, a violência não é algo natural, e não faz parte da natureza humana. A autora encontra problemas naqueles que procuram justificar ou sustentar a explicação para o fenômeno da violência através de argumentos biológicos.

A pensadora enfatiza em seu ensaio, que não pretende ser um tratado que esgota o tema da violência, mas que busca refletir sobre suas causas e natureza, a partir do caráter social e político da violência, trazendo argumentos que podem auxiliar muito o pensar da violência na sociedade e na política contemporânea.

O objetivo desde artigo também não foi exaurir o tema, mas apresentar essa distinção importante para Arendt e mostrar sua posição, no sentido de refletir a natureza da violência e sua distinção em relação ao poder.

Para Arendt, o poder é fundamentado no apoio, tácito ou explícito, e ainda, no número de pessoas que consentem com ele, e não nos meios de violência que se dispõe. Para Arendt, a violência acontece quando o poder está ausente.

${ }^{27}$ ARENDT, Hannah. Sobre a violência. Rio de Janeiro: Editora Civilização Brasileira, 2011, p. 145; DUARTE, André. O pensamento à sombra da ruptura: política e filosofia em Hannah Arendt. São Paulo: Paz e Terra, 2000.

${ }^{28}$ ARENDT, Hannah. Sobre a violência. Rio de Janeiro: Editora Civilização Brasileira, 2011, p. 146; DUARTE, André. O pensamento à sombra da ruptura: política e filosofia em Hannah Arendt. São Paulo: Paz e Terra, 2000. 
O artigo buscou demonstrar ainda, ao final, que o papel do direito e das leis, de acordo com Arendt não tem a ver com a ideia conservadora que considera as leis e o direito imutáveis, pelo contrário, para Arendt a mudança faz parte da condição humana.

\section{REFERÊNCIAS}

ARENDT, Hannah. Sobre a violência. Rio de Janeiro: Editora Civilização Brasileira, 2011.

On Violence. New York: Harcourt, 1969.

. Macht und Gewalt. München: Piper Verlag, 2014.

. On Revolution. New York: Viking Press, 1963

. Human Condition. Chicago: The University of Chicago Press, 1998.

The origins of totalitarianism. New York: Harcourt, 1966.

DUARTE, André. O pensamento à sombra da ruptura: política e filosofia em Hannah Arendt. São Paulo: Paz e Terra, 2000.

SANTOS, Silvia Gombi. Em busca de um lugar no mundo: o conceito de violência em Hannah Arendt. São Paulo: Editora Perspectiva, 2011. 